\title{
Some Theorems in the Existence, Uniqueness and Stability solutions of Volterra Integrals Equations
}

\author{
${ }^{1}$ Raad N. Butris, ${ }^{2}$ Sebar T. Qader \\ 1,2Department of Mathematics, Collage of Basic Education, University of Duhok, Kurdistan Region - Iraq
}

\begin{abstract}
The aim of this work is to study the existence, uniqueness and stability solutions of Volterra integrals equations by using both Picard approximation and Banach fixed point theorems. This study leads to develop and extend the above theorems and to expand the results obtained by Butris.
\end{abstract}

Keywords: Picard approximation method, Banach fixed point theorem, existence, uniqueness and stability solutions.

\section{Introduction}

\subsection{Literature Review}

Some results on the existence, uniqueness and stability solutions of Volterra integrals equations have been obtain by Picard approximation and Banach fixed point theorems that were proposed by [7]. As well as, these results applied in many studies $[2,4,5,6,8]$.

Vito Volterra (1860-1940) worked on integral equations and especially in finding inverse of integral operators, particularly in theory of integral equations and are contribution concerning nonlinear functional analysis [3]. Butris [1] used Picard approximation and Banach fixed point theorems for studying the existence and uniqueness solutions of the following integral equation of Volterra type.

$$
u(t)=f(t)+\int_{0}^{t} F(t, s) u(s) d s, \quad(t \in[0, h])
$$

In this equation the functions $f(t)$ and $F(t, s)$ are continuous on finite interval $0 \leq \mathrm{t} \leq \mathrm{h}$ and the square region $0 \leq \mathrm{t} \leq \mathrm{h}, 0 \leq \mathrm{s} \leq \mathrm{h}$, respectively.

Academic Journal of Nawroz University

(AJNU) Volume 8, No 4 (2019).

Regular research paper : Published 28 Dec 2019

Corresponding author's e-mail : raad.butris@gmail.com

Copyright (C2018 1'Raad N. Butris, 2Sebar T. Qader.

This is an open access article distributed under the Creative

Commons Attribution License.
This work extended some results of Butris[1] to Volterra types, by using also both Picard approximation and Banach fixed point theorems which are given by[7].

Consider the following integrals equations of Volterra types

$$
u(t)=u_{0}+f(t)+\int_{-\infty}^{t} K(t, s) F(s, u(s), w(s)) d s \ldots
$$

and

$$
w(t)=u_{0}+g(t)+\int_{-\infty}^{t} H(t, s) G(s, u(s), w(s)) d s
$$

where

$\mathrm{u} \in \mathrm{D}_{1} \subseteq \mathrm{R}^{\mathrm{n}}, \mathrm{w} \in \mathrm{D}_{2} \subseteq \mathrm{R}^{\mathrm{m}}, \mathrm{D}_{1}, \mathrm{D}_{2}$ are a compact domains.

The vector functionsf $(\mathrm{t}), \mathrm{g}(\mathrm{t}), \mathrm{F}(\mathrm{t}, \mathrm{u}, \mathrm{w}) \operatorname{and} \mathrm{G}(\mathrm{t}, \mathrm{u}, \mathrm{w})$ continuous on the domain

$$
\mathrm{D}=\left\{(\mathrm{t}, \mathrm{u}, \mathrm{w}) ; \mathrm{t} \in \mathrm{R}^{1}, \mathrm{u} \in \mathrm{D}_{1}, \mathrm{w} \in \mathrm{D}_{2}\right\} .
$$

Suppose that the vector functions $\mathrm{F}(\mathrm{t}, \mathrm{u}, \mathrm{w})$ and $\mathrm{f}(\mathrm{t}, \mathrm{u}, \mathrm{w})$ satisfy the following inequalities

$$
\begin{aligned}
& \left.\qquad \begin{array}{l}
\|\mathrm{F}(\mathrm{t}, \mathrm{u}, \mathrm{w})\| \leq \mathrm{M}_{1}, \quad\|\mathrm{G}(\mathrm{t}, \mathrm{u}, \mathrm{w})\| \leq \mathrm{M}_{2} \\
\left\|\mathrm{~F}\left(\mathrm{t}, \mathrm{u}_{1}, \mathrm{w}_{1}\right)-\mathrm{F}\left(\mathrm{t}, \mathrm{u}_{2}, \mathrm{w}_{2}\right)\right\| \leq \mathrm{K}_{1}\left\|\mathrm{u}_{1}-\mathrm{u}_{2}\right\|+\mathrm{K}_{2}\left\|\mathrm{w}_{1}-\mathrm{w}_{2}\right\| \\
\left\|\mathrm{G}\left(\mathrm{t}, \mathrm{u}_{1}, \mathrm{w}_{1}\right)-\mathrm{G}\left(\mathrm{t}, \mathrm{u}_{2}, \mathrm{w}_{2}\right)\right\| \leq \mathrm{L}_{1}\left\|\mathrm{u}_{1}-\mathrm{u}_{2}\right\|+\mathrm{L}_{2}\left\|\mathrm{w}_{1}-\mathrm{w}_{2}\right\|
\end{array}\right\} \\
& \text { For all } \mathrm{t} \in \mathrm{R}^{1}, \quad \mathrm{u}, \mathrm{u}_{1}, \mathrm{u}_{2} \in \mathrm{D}_{1}, \mathrm{w}, \mathrm{w}_{1}, \mathrm{w}_{2} \in \mathrm{D}_{2} \quad \text { where } \\
& \mathrm{M}_{1}, \mathrm{M}_{2}, \mathrm{~K}_{1}, \mathrm{~K}_{2} \text { and } \mathrm{L}_{1}, \mathrm{~L}_{2} \text { are positive constant. This } \\
& \text { provides }
\end{aligned}
$$




$$
\|\mathrm{K}(\mathrm{t}, \mathrm{s})\| \leq \delta_{1} \mathrm{e}^{-\lambda_{1}(\mathrm{t}-\mathrm{s})},\|\mathrm{H}(\mathrm{t}, \mathrm{s})\| \leq \delta_{2} \mathrm{e}^{-\lambda_{2}(\mathrm{t}-\mathrm{s})}
$$

where $\delta_{1}, \delta_{2}, \lambda_{1}, \lambda_{2}>0$, with $\|\|=.\max _{\mathrm{t} \in[0, \mathrm{~h}]} \mid$. $\mid$.

The non-empty sets is defined by:-

$$
\left.\begin{array}{l}
\mathrm{D}_{\mathrm{f}}=\mathrm{D}_{1}-\mathrm{M}_{1} \frac{\delta_{1}}{\lambda_{1}} \\
\mathrm{D}_{\mathrm{g}}=\mathrm{D}_{2}-\mathrm{M}_{2} \frac{\delta_{2}}{\lambda_{2}}
\end{array}\right\}
$$

Furthermore, assume that the largest Eigen-value of the matrix

$$
\mathrm{Q}=\left(\begin{array}{cc}
\mathrm{K}_{1} \frac{\delta_{1}}{\lambda_{1}} \mathrm{~h} & \mathrm{~K}_{2} \frac{\delta_{1}}{\lambda_{1}} \mathrm{~h} \\
\mathrm{~L}_{1} \frac{\delta_{2}}{\lambda_{2}} \mathrm{~h} & \mathrm{~L}_{2} \frac{\delta_{2}}{\lambda_{2}} \mathrm{~h}
\end{array}\right)
$$

less than one,

$$
\text { i.e } \lambda \max (Q)<1
$$

where $\quad \lambda_{\max }=\frac{(a+d) \pm \sqrt{(a+d)^{2}-4(a d-b c)}}{2}$

where $\quad \mathrm{a}=\mathrm{K}_{1} \frac{\delta_{1}}{\lambda_{1}} \mathrm{~h}, \mathrm{~b}=\mathrm{K}_{2} \frac{\delta_{1}}{\lambda_{1}} \mathrm{~h}, \mathrm{c}=\mathrm{L}_{1} \frac{\delta_{2}}{\lambda_{2}}, \mathrm{hd}=\mathrm{L}_{2} \frac{\delta_{2}}{\lambda_{2}} \mathrm{~h}$.

Define the sequence of a functions $\left\{u_{m}(t), w_{m}(t)\right\}_{m=0}^{\infty}$ by the following

$u_{m}(t)=u_{0}+f(t)+\int_{-\infty}^{t} K(t, s) F\left(s, u_{m-1}(s), w_{m-1}(s)\right) d s$

with ... (8)

$$
\mathrm{u}_{0}(0)=\mathrm{u}_{0}+\mathrm{f}(\mathrm{t}
$$

and

$w_{m}(t)=w_{0}+g(t)+\int_{-\infty}^{t} H(t, s) G\left(s, u_{m-1}(s), w_{m-1}(s)\right) d s$

...(9)

$\mathrm{w}_{0}(0)=\mathrm{w}_{0}+\mathrm{g}(\mathrm{t})$

\subsection{Preliminaries}

Some definitions and theorems which needed are given in this work.

Definition 1.[1].

Let $(\mathrm{D},\|\|$.$) be normed space if \mathrm{T}$ maps $\mathrm{D}$ into itself, $\mathrm{T}$ is a contraction mapping on $D$ if there exists $\propto \in R^{1}$ with $0<\propto<1$ such that

$$
\|\operatorname{Tx}(\mathrm{t})-\operatorname{Ty}(\mathrm{t})\| \leq \alpha\|\mathrm{x}(\mathrm{t})-\mathrm{y}(\mathrm{t})\|,(\mathrm{x}(\mathrm{t}), \mathrm{y}(\mathrm{t})) \in \mathrm{D} .
$$

Definition 2.[1] (Lipchitz Condition)

Let $f$ be a continuous function defined on a domain $\mathrm{D}=\{(\mathrm{t}, \mathrm{x}): \mathrm{a} \leq \mathrm{t} \leq \mathrm{b}, \mathrm{c} \leq \mathrm{x} \leq \mathrm{d}\}$. Then $\mathrm{f}$ is said to satisfy a Lipchitz condition in the variable $\mathrm{x}$ on $\mathrm{D}$, provided that a constant $\mathrm{L}>0$ exists with property that $\mid \mathrm{f}\left(\mathrm{t}, \mathrm{x}_{1}\right)-$ $\mathrm{f}\left(\mathrm{t}, \mathrm{x}_{2}\right)|\leq \mathrm{L}| \mathrm{x}_{1}-\mathrm{x}_{2} \mid, \quad$ for all $\quad\left(\mathrm{t}, \mathrm{x}_{1}\right),\left(\mathrm{t}, \mathrm{x}_{2}\right) \in \mathrm{D}$. The constant $\mathrm{L}$ is called a Lipchitz constant for $\mathrm{f}$.

Definition 3.[8](Stability)

A solution $\mathrm{x}(\mathrm{t})$ is said to be stable if for each $\varepsilon>0$, there exists a $\delta>0$ such that any solution $\breve{x}(t)$ which satisfies $\left\|\check{\mathrm{x}}\left(\mathrm{t}_{0}\right)-\mathrm{x}\left(\mathrm{t}_{0}\right)\right\|<\delta$ for some $\mathrm{t}_{0}$, also satisfies $\left\|\check{\mathrm{x}}\left(\mathrm{t}_{0}\right)-\mathrm{x}\left(\mathrm{t}_{0}\right)\right\|<\varepsilon$ for all $\mathrm{t} \geq \mathrm{t}_{0}$.

\section{Definition 4.[8]}

Let $\dot{x}=f(t, x)$ be a system of differential equation and let $\mathrm{x}(\mathrm{t})$ be a solution defined for $\mathrm{t} \geq \mathrm{t}_{0}$. The solution $\mathrm{x}(\mathrm{t})$ is said to be stable if for each $\varepsilon>0$ there exists a positive $\delta=\delta(\epsilon)$, such that any solution $\overline{\mathrm{x}}(\mathrm{t})$ which is defined at $\mathrm{t}=\mathrm{t}_{0}$ and satisfied $\left\|\overline{\mathrm{x}}\left(\mathrm{x}_{0}\right)-\mathrm{x}\left(\mathrm{t}_{0}\right)\right\| \leq \delta$ is defined for all $t \geq t_{0}$ and satisfies $\|\bar{x}(t)-x(t)\|<\varepsilon$ for all $t \geq t_{0}$.

Definition 5. [1]

Let $\left\{\mathrm{f}_{\mathrm{m}}(\mathrm{t})\right\}_{\mathrm{m}=0}^{\infty}$ be a sequence of functionsf defined on a set $\mathrm{E} \subseteq \mathrm{R}^{1}$ we say that $\left\{\mathrm{f}_{\mathrm{m}}(\mathrm{t})\right\}_{\mathrm{m}=0}^{\infty}$ converges uniformly to the limit function $\mathrm{f}$ on $\mathrm{E}$ if given $\varepsilon>0$ there exists a positive integer such that $\left|f_{m}(t)-f(t)\right|<\varepsilon$,

$(\mathrm{m} \geq \mathrm{N}, \mathrm{t} \in \mathrm{E})$.

Theorem 1.[1](Banach fixed pointI theorem)

Let $\mathrm{E}$ be a Banach space. If $\mathrm{T}$ is a contraction mapping on $\mathrm{E}$, then $\mathrm{T}$ has one and only fixed point in $\mathrm{E}$.

Theorem 2.[1]

Assume that $\mathrm{c}[0, \mathrm{~h}]$ be a space of all continuous functions on $[0, \mathrm{~h}]$, for all $\mathrm{x}(\mathrm{t}) \in \mathrm{c}[0, \mathrm{~h}]$, we denoted ॥ $x(t) \|=\max _{t \in[0, h]}|x(t)|$. Then $(c[0, h],\|\|$.$) is a Banach space.$

\section{i.Existence Solutions of (1) and (2).}

The investigation of the existence solution of (1) and(2) will be the introduced by the following theorem:-

Theorem3. Let the vector functions $f(t), g(t)$ and $\mathrm{F}(\mathrm{t}, \mathrm{u}, \mathrm{w}), \mathrm{G}(\mathrm{t}, \mathrm{u}, \mathrm{w})$ defined and continuous on the domain (3) suppose these functions are satisfying the inequalities (4),(5) and the conditions (6), (7). Then 
there exist a sequence of functions (8) and (9) converges uniformly on the domain

$$
\mathrm{G}^{*}=\left\{\left(\mathrm{t}, \mathrm{u}_{0}, \mathrm{w}_{0}\right) \in[0, \mathrm{~h}] \times \mathrm{D}_{1} \times \mathrm{D}_{2}\right\}
$$

to the limit vector function $\left(\begin{array}{c}u(t) \\ w(t)\end{array}\right)$ which is a continuous on the domain (3) and satisfies the following integral equations:-

$\left(\begin{array}{c}\mathrm{u}(\mathrm{t}) \\ \mathrm{w}(\mathrm{t})\end{array}\right)=$

$\left(\begin{array}{c}u_{0}+f(t)+\int_{-\infty}^{t} K(t, s) F\left(s, u_{0}\left(t, u_{0}, w_{0}\right), w_{0}\left(t, u_{0}, w_{0}\right)\right) d s \\ w_{0}+g(t)+\int_{-\infty}^{t} H(t, s) G\left(s, u_{0}\left(t, u_{0}, w_{0}\right), w_{0}\left(t, u_{0}, w_{0}\right)\right) d s\end{array}\right)$

and it is exist solution of (1) and(2).

Provide that

$$
\left(\begin{array}{c}
\left\|\mathrm{u}_{\mathrm{m}}(\mathrm{t})-\mathrm{u}_{0}\right\| \\
\left\|\mathrm{w}_{\mathrm{m}}(\mathrm{t})-\mathrm{w}_{0}\right\|
\end{array}\right) \leq\left(\begin{array}{c}
\mathrm{M}_{1} \frac{\delta_{1}}{\lambda_{1}} \\
\mathrm{M}_{2} \frac{\delta_{2}}{\lambda_{2}}
\end{array}\right) \ldots(12)
$$

and

$\left(\begin{array}{c}\left\|u_{m+1}(t)-u_{0}(t)\right\| \\ \left\|w_{m+1}(t)-w_{0}(t)\right\|\end{array}\right) \leq Q^{m}(E-Q)^{-1} \Psi_{0}$

for all $\mathrm{t} \in[0, \mathrm{~h}]$ and $\mathrm{u}_{0} \in \mathrm{D}_{\mathrm{f}}, \mathrm{w}_{0} \in \mathrm{D}_{\mathrm{g}}, \mathrm{m}=0,1,2, \ldots \ldots$

where

$\Psi_{0}=\left(\begin{array}{l}M_{1} \frac{\delta_{1}}{\lambda_{1}} \\ M_{2} \frac{\delta_{2}}{\lambda_{2}}\end{array}\right)$

By mathematical indication we can prove that

$$
\left\|\mathrm{u}_{\mathrm{m}}(\mathrm{t})-\mathrm{u}_{0}\right\| \leq \mathrm{M}_{1} \frac{\delta_{1}}{\lambda_{1}}
$$

That is $\mathrm{u}_{\mathrm{m}}(\mathrm{t}) \in \mathrm{D}_{\mathrm{F}}$, for all $\mathrm{t} \in[0, \mathrm{~h}]$ and $\mathrm{u}_{0} \in \mathrm{D}_{\mathrm{F}}$.

Similarly, from the sequence of functions (9) and we obtain that

$$
\left\|\mathrm{w}_{\mathrm{m}}(\mathrm{t})-\mathrm{w}_{0}\right\| \leq \mathrm{M}_{2} \frac{\delta_{2}}{\lambda_{2}}
$$

That is $w_{m}(t) \in D_{2}$, for all $t \in[0, h]$ and $w_{0} \in D_{g}$.

Next we shall prove that the sequences of functions (8) and (9) converge uniformly on the domain (10). Then by mathematics induction we have $\left\|\mathrm{u}_{\mathrm{m}+1}(\mathrm{t})-\mathrm{u}_{\mathrm{m}}(\mathrm{t})\right\| \leq \frac{\delta_{1} \mathrm{~h}}{\lambda_{1}}\left(\mathrm{~K}_{1}\left\|\mathrm{u}_{\mathrm{m}}(\mathrm{t})-\mathrm{u}_{\mathrm{m}-1}(\mathrm{t})\right\|+\right.$

$$
\left.\mathrm{K}_{2}\left\|\mathrm{w}_{\mathrm{m}}(\mathrm{t})-\mathrm{w}_{\mathrm{m}-1}(\mathrm{t})\right\|\right)
$$

and

$\left\|\mathrm{w}_{\mathrm{m}+1}(\mathrm{t})-\mathrm{w}_{\mathrm{m}}(\mathrm{t})\right\| \leq \frac{\delta_{2} \mathrm{~h}}{\lambda_{2}}\left(\mathrm{~L}_{1}\left\|\mathrm{u}_{\mathrm{m}}(\mathrm{t})-\mathrm{u}_{\mathrm{m}-1}(\mathrm{t})\right\|+\right.$

$\left.\mathrm{L}_{2}\left\|\mathrm{w}_{\mathrm{m}}(\mathrm{t})-\mathrm{w}_{\mathrm{m}-1}(\mathrm{t})\right\|\right)$

Rewrite (14) and (15) in a vector form we get

$\Psi_{\mathrm{m}+1} \leq \mathrm{Q}(\mathrm{t}) \Psi_{\mathrm{m}}$

where

$\Psi_{\mathrm{m}+1}=\left(\begin{array}{l}\left\|\mathrm{u}_{\mathrm{m}+1}(\mathrm{t})-\mathrm{u}_{\mathrm{m}}(\mathrm{t})\right\| \\ \left\|\mathrm{w}_{\mathrm{m}+1}(\mathrm{t})-\mathrm{w}_{\mathrm{m}}(\mathrm{t})\right\|\end{array}\right)$

$\Psi_{\mathrm{m}}=\left(\begin{array}{c}\left\|\mathrm{u}_{\mathrm{m}}(\mathrm{t})-\mathrm{u}_{\mathrm{m}-1}(\mathrm{t})\right\| \\ \left\|\mathrm{w}_{\mathrm{m}}(\mathrm{t})-\mathrm{w}_{\mathrm{m}-1}(\mathrm{t})\right\|\end{array}\right)$,

and

$\mathrm{Q}(\mathrm{t})=\left(\begin{array}{cc}\mathrm{K}_{1} \frac{\delta_{1}}{\lambda_{1}} \mathrm{t} & \mathrm{K}_{2} \frac{\delta_{1}}{\lambda_{1}} \mathrm{t} \\ \mathrm{L}_{1} \frac{\delta_{2}}{\lambda_{2}} \mathrm{t} & \mathrm{L}_{2} \frac{\delta_{2}}{\lambda_{2}} \mathrm{t}\end{array}\right)$

Now we take the maximum value for the both sides of the inequality (18)

$\Psi_{\mathrm{m}+1} \leq \mathrm{Q} \Psi_{\mathrm{m}}$

where $\mathrm{Q}=\max _{\mathrm{t} \in[0, \mathrm{~h}]} \mathrm{Q}(\mathrm{t})$.

By repetition of (19) we find that $\Psi_{\mathrm{m}+1} \leq \mathrm{Q}^{\mathrm{m}} \Psi_{0}$ and also we get

$\sum_{\mathrm{i}=1}^{\mathrm{m}} \Psi_{\mathrm{i}} \leq \sum_{\mathrm{i}=1}^{\infty} \mathrm{Q}^{\mathrm{i}-1} \Psi_{0}$

Using the condition (17), thus the sequence of functions (8) and (9) are uniformly convergent, that is

$\lim _{\mathrm{m} \rightarrow \infty} \sum_{\mathrm{i}=1}^{\mathrm{m}} \mathrm{Q}^{\mathrm{m}-1} \Psi_{0}=\sum_{\mathrm{i}=1}^{\infty} \mathrm{Q}^{\mathrm{m}-1} \Psi_{0}=(1-\mathrm{Q})^{-1} \Psi_{0}$

Let

$\lim _{m \rightarrow \infty}\left(\begin{array}{c}u_{m}(t) \\ w_{m}(t)\end{array}\right)=\left(\begin{array}{c}u(t) \\ w(t)\end{array}\right)$

Since the sequence of function (8) and (9) are defined and continuous in the domain (3) then the limit vector function $\left(\begin{array}{l}u(t) \\ w(t)\end{array}\right)$ is also defined and continuous in the domain (3).

By using the conditions and inequalities of a theorem , we can prove that the inequalities (12) and (13) will be satisfied for all $t \in[0, h], u_{0} \in D_{F}, w_{0} \in D_{G}, m=0,1,2 \ldots$.

ii.Uniqueness Solutions of (1) and (2). 
The investigation of the uniqueness solutions of (1) and (2) will be introduced by :-

Thorem4. Let all assumptions and conditions of Theorem 3 be satisfied.

Then the solution $\left(\begin{array}{l}u(t) \\ w(t)\end{array}\right)$ is a unique of (1) and (2).

Proof. Let $\left(\begin{array}{l}\breve{u}(t) \\ \breve{w}(t)\end{array}\right)$ be another solution of (1) and (2), that is

$\breve{\mathrm{u}}(\mathrm{t})=\mathrm{u}_{0}+\mathrm{f}(\mathrm{t})+\int_{-\infty}^{\mathrm{t}} \mathrm{K}(\mathrm{t}, \mathrm{s}) \mathrm{F}(\mathrm{s}, \breve{\mathrm{u}}(\mathrm{s}), \breve{\mathrm{w}}(\mathrm{s})) \mathrm{ds}$

and

$\breve{w}(t)=w_{0}+g(t)+\int_{-\infty}^{t} H(t, s) G(s, \breve{u}(s), \breve{w}(s)) d s$

Assuming

$\|\mathrm{u}(\mathrm{t})-\breve{\mathrm{u}}(\mathrm{t})\| \leq \frac{\delta_{1} \mathrm{~h}}{\lambda_{1}}\left(\mathrm{~K}_{1}\|\mathrm{u}(\mathrm{s})-\breve{\mathrm{u}}(\mathrm{t})\|+\mathrm{K}_{2} \| \mathrm{w}(\mathrm{s})-\right.$

$\breve{w}(\mathrm{t}) \|$

and

$\|\mathrm{w}(\mathrm{t})-\breve{\mathrm{w}}(\mathrm{t})\| \leq \frac{\delta_{2} \mathrm{~h}}{\lambda_{2}}\left(\mathrm{~L}_{1}\|\mathrm{u}(\mathrm{t})-\breve{\mathrm{u}}(\mathrm{t})\|+\mathrm{L}_{2} \| \mathrm{w}_{\mathrm{m}}(\mathrm{t})-\right.$

$\breve{w}(t) \|$

$\left(\begin{array}{c}\|\mathrm{u}(\mathrm{t})-\breve{\mathrm{u}}(\mathrm{t})\| \\ \|\mathrm{w}(\mathrm{t})-\breve{w}(\mathrm{t})\|\end{array}\right) \leq \mathrm{Q}\left(\begin{array}{c}\|\mathrm{u}(\mathrm{t})-\breve{\mathrm{u}}(\mathrm{t})\| \\ \|\mathrm{w}(\mathrm{t})-\breve{\mathrm{w}}(\mathrm{t})\|\end{array}\right)$

...(25)

By iterating the inequality (23) we have

$\left(\begin{array}{c}\|u(t)-\breve{u}(t)\| \\ \|w(t)-\breve{w}(t)\|\end{array}\right) \leq Q^{m}\left(\begin{array}{c}\|u(t)-\breve{u}(t)\| \\ \|w(t)-\breve{w}(t)\|\end{array}\right)$

Then by the condition (17), we find that

$\left(\begin{array}{c}\|\mathrm{u}(\mathrm{t})-\breve{\mathrm{u}}(\mathrm{t})\| \\ \|\mathrm{w}(\mathrm{t})-\breve{\mathrm{w}}(\mathrm{t})\|\end{array}\right) \rightarrow\left(\begin{array}{l}0 \\ 0\end{array}\right)$

$\operatorname{Thus}\left(\begin{array}{c}\mathrm{u}(\mathrm{t}) \\ \mathrm{w}(\mathrm{t})\end{array}\right)=\left(\begin{array}{c}\breve{\mathrm{u}}(\mathrm{t}) \\ \breve{w}(\mathrm{t})\end{array}\right)$.

Hence the solutions $\left(\begin{array}{l}u(t) \\ w(t)\end{array}\right)$ of (1) and (2) is a unique on the domain (3).

V. Stability Solutions of (1) and (2).

In this section, we can study the stability solutions of Volterra integral equations

(1) and (2) respectively.

Theorem5. Suppose that the functions $\mathrm{F}(\mathrm{t}, \mathrm{u}, \mathrm{w})$ and $f(t, u, w)$ be continuous in the domain (3) and satisfy the inequalities (4) and (6). Then the solution (11) is stable for all $\mathrm{t} \geq 0$.

Proof: Taking

$\|\mathrm{u}(\mathrm{t})-\overline{\mathrm{u}}(\mathrm{t})\| \leq \frac{\delta_{1}}{\lambda_{1}} \mathrm{t}\left\|\mathrm{u}_{0}-\overline{\mathrm{u}}_{0}\right\|+\frac{\delta_{1} \mathrm{M}_{1}}{\lambda_{1}}\left[\mathrm{~K}_{1}\|\mathrm{u}(\mathrm{t})-\overline{\mathrm{u}}(\mathrm{t})\|\right.$

$\left.+\mathrm{K}_{2}\|\mathrm{w}(\mathrm{t})-\overline{\mathrm{w}}(\mathrm{t})\|\right]$

and

$\|\mathrm{w}(\mathrm{t})-\overline{\mathrm{w}}(\mathrm{t})\| \leq \frac{\delta_{2}}{\lambda_{2}} \mathrm{t}\left\|\mathrm{w}_{0}-\overline{\mathrm{w}}_{0}\right\|+\frac{\delta_{2}}{\lambda_{2}} \mathrm{M}_{2}\left[\mathrm{~L}_{1} \| \mathrm{u}(\mathrm{t})-\right.$

$\left.\overline{\mathrm{u}}(\mathrm{t})\left\|+\mathrm{L}_{2}\right\| \mathrm{w}(\mathrm{t})-\overline{\mathrm{w}}(\mathrm{t}) \|\right]$

where

$\overline{\mathrm{u}}=\mathrm{u}_{0}+\mathrm{f}(\mathrm{t})+\int_{-\infty}^{\mathrm{t}} \mathrm{K}(\mathrm{t}, \mathrm{s}) \mathrm{F}(\mathrm{s}, \overline{\mathrm{u}}(\mathrm{s}), \overline{\mathrm{w}}(\mathrm{s})) \mathrm{ds}$

and

$\overline{\mathrm{w}}=\mathrm{w}_{0}+\mathrm{g}(\mathrm{t})+\int_{-\infty}^{\mathrm{t}} \mathrm{H}(\mathrm{t}, \mathrm{s}) \mathrm{G}(\mathrm{s}, \overline{\mathrm{u}}(\mathrm{s}), \overline{\mathrm{w}}(\mathrm{s})) \mathrm{ds}$

Rewrite (26) and (27) in a vector form that is

$$
\begin{aligned}
& \left(\begin{array}{c}
\|\mathrm{u}(\mathrm{t})-\overline{\mathrm{u}}(\mathrm{t})\| \\
\|\mathrm{w}(\mathrm{t})-\overline{\mathrm{w}}(\mathrm{t})\|
\end{array}\right) \leq\left(\begin{array}{c}
\left\|\mathrm{u}_{0}-\overline{\mathrm{u}}_{0}\right\| \\
\left\|\mathrm{w}_{0}-\overline{\mathrm{w}}_{0}\right\|
\end{array}\right)+ \\
& \quad \mathrm{Q}\left(\begin{array}{c}
\|\mathrm{u}(\mathrm{t})-\overline{\mathrm{u}}(\mathrm{t})\| \\
\|\mathrm{w}(\mathrm{t})-\overline{\mathrm{w}}(\mathrm{t})\|
\end{array}\right) \text { For }\left\|\mathrm{u}_{0}-\overline{\mathrm{u}}_{0}\right\| \leq \delta_{1},\left\|\mathrm{w}_{0}-\overline{\mathrm{w}}_{0}\right\| \leq \delta_{2}
\end{aligned}
$$

then

$\left(\begin{array}{c}\|\mathrm{u}(\mathrm{t})-\overline{\mathrm{u}}(\mathrm{t})\| \\ \|\mathrm{w}(\mathrm{t})-\overline{\mathrm{w}}(\mathrm{t})\|\end{array}\right) \leq\left(\begin{array}{c}\delta_{1} \\ \delta_{2}\end{array}\right)+\mathrm{Q}\left(\begin{array}{c}\|\mathrm{u}(\mathrm{t})-\overline{\mathrm{u}}(\mathrm{t})\| \\ \|\mathrm{w}(\mathrm{t})-\overline{\mathrm{w}}(\mathrm{t})\|\end{array}\right)$

By using the condition (17) we have

$\left(\begin{array}{c}\|\mathrm{u}(\mathrm{t})-\overline{\mathrm{u}}(\mathrm{t})\| \\ \|\mathrm{w}(\mathrm{t})-\overline{\mathrm{w}}(\mathrm{t})\|\end{array}\right) \leq\left(\begin{array}{c}\epsilon_{1} \\ \epsilon_{2}\end{array}\right), \quad \epsilon_{1}, \epsilon_{2} \geq 0$.

Also by using the definition of the stability [8] we find that $\left(\begin{array}{l}\overline{\mathrm{u}}(\mathrm{t}) \\ \overline{\mathrm{w}}(\mathrm{t})\end{array}\right)$ is a stable solution $\mathrm{t} \geq 0$ of $(1)$ and (2).

\section{Another results of the solutions (1) and (2).}

In this section, we can study the solution of Volterra integrals equations (1) and (2) by using:-

Theorem6. With the hypotheses and all conditions of theorem (1) the solutions of integral equations (1) and (2) are a unique on the domain (3). 
Proof: Assume that $(\mathrm{C}[0, \mathrm{~h}],\|\|$.$) is a Banach spaces.$ Define a mapping $\mathrm{T}$ on $\mathrm{C}[0, \mathrm{~h}]$ by :-

$\mathrm{Tu}^{*}(\mathrm{t})=\mathrm{u}_{0}+\mathrm{f}(\mathrm{t})+\int_{-\infty}^{\mathrm{t}} \mathrm{K}(\mathrm{s}, \mathrm{t}) \mathrm{F}(\mathrm{s}, \mathrm{u}(\mathrm{s}), \mathrm{w}(\mathrm{s})) \mathrm{ds}$

and

$\mathrm{Tw}^{*}(\mathrm{t})=\mathrm{u}_{0}+\mathrm{g}(\mathrm{t})+\int_{-\infty}^{\mathrm{t}} \mathrm{H}(\mathrm{s}, \mathrm{t}) \mathrm{G}(\mathrm{s}, \mathrm{u}(\mathrm{s}), \mathrm{w}(\mathrm{s})) \mathrm{ds}$

then

$$
\begin{aligned}
& \left\|\mathrm{Tu}(\mathrm{t})-\mathrm{Tu}^{*}(\mathrm{t})\right\| \leq \frac{\delta_{1} \mathrm{~h}}{\lambda_{1}}\left(\mathrm{~K}_{1}\left\|\mathrm{u}(\mathrm{s})-\mathrm{u}^{*}(\mathrm{t})\right\|+\right. \\
& \left.\mathrm{K}_{2}\left\|\mathrm{w}(\mathrm{s})-\mathrm{w}^{*}(\mathrm{t})\right\|\right) \quad \ldots(28) \\
& \text { and }
\end{aligned}
$$

$$
\begin{gathered}
\left\|\mathrm{Tw}(\mathrm{t})-\mathrm{Tw}^{*}(\mathrm{t})\right\| \leq \frac{\delta_{2} \mathrm{~h}}{\lambda_{2}}\left(\mathrm{~L}_{1}\left\|\mathrm{u}(\mathrm{t})-\mathrm{u}^{*}(\mathrm{t})\right\|+\right. \\
\left.\mathrm{L}_{2}\left\|\mathrm{w}_{\mathrm{m}}(\mathrm{t})-\mathrm{w}^{*}(\mathrm{t})\right\|\right)
\end{gathered}
$$

Rewrite (28) and (29) in a vector form

$$
\begin{aligned}
& \left(\begin{array}{c}
\left\|\mathrm{Tu}(\mathrm{t})-\mathrm{Tu}^{*}(\mathrm{t})\right\| \\
\left\|\mathrm{Tw}(\mathrm{t})-\mathrm{Tw}^{*}(\mathrm{t})\right\|
\end{array}\right) \\
& \leq\left(\begin{array}{cc}
\mathrm{K}_{1} \frac{\delta_{1}}{\lambda_{1}} \mathrm{~h} & \mathrm{~K}_{2} \frac{\delta_{1}}{\lambda_{1}} \mathrm{~h} \\
\mathrm{~L}_{1} \frac{\delta_{2}}{\lambda_{2}} \mathrm{~h} & \mathrm{~L}_{2} \frac{\delta_{2}}{\lambda_{2}} \mathrm{~h}
\end{array}\right)\left(\begin{array}{l}
\left\|\mathrm{u}(\mathrm{t})-\mathrm{u}^{*}(\mathrm{t})\right\| \\
\left\|\mathrm{w}(\mathrm{t})-\mathrm{w}^{*}(\mathrm{t})\right\|
\end{array}\right)
\end{aligned}
$$

By using the condition (7), so that

$$
\left(\begin{array}{c}
\mathrm{Tu}^{*}(t) \\
\mathrm{Tw}^{*}(\mathrm{t})
\end{array}\right) \text { is a contraction mapping on }[0, \mathrm{~h}] \text {. By using }
$$

Banach fixed point theorem such that

$$
\left(\begin{array}{c}
\mathrm{Tu}^{*}(t) \\
\operatorname{Tw}^{*}(t)
\end{array}\right)=\left(\begin{array}{c}
\mathrm{Tu}(\mathrm{t}) \\
\operatorname{Tw}(\mathrm{t})
\end{array}\right) \text { is a fixed point on } \mathrm{C}[0, \mathrm{~h}]
$$

Then

$\left(\begin{array}{c}\operatorname{Tu}^{*}(t) \\ \operatorname{Tw}^{*}(t)\end{array}\right)$ is exist and unique solution of (1) and (2).

Note. Picard approximation method gives us a global solution for Volterra integral equations (1) and (2). While contraction mapping theorem gives us a local solutions for Voltterra integrals equations (1) and (2).

\section{References}

1. R. N. Butris, Solutions for the Volterra integral equations of the second kind, university of Mosul ,Mosul, Iraq, (1984) .

2. R. N. Butris, and Rafeq, A. Sh., Existence and Uniqueness
Solution for Nonlinear Volterra Integral Equation, J. Duhok Univ. Vol. 14, No. 1, (Pure and Eng. Sciences), (2011),25-29.

3. C. Corduneanu, I.W. Sanberg, Volterra Equations and Aplications, Gordon and Breach Science Publisher. Vol. 10, (2000), xiii pages.

4. E. A. Coddington, An introduction to Ordinary Differential Equations ,Prentice-Hall,Inc.Englewood Cliffs,N.J., (1961), 292 pages.

5. F,G Tricomi, (1965), Integral Equations, Turin University, Turin, Italy.

6. E.A. Goma, Sccessives approximation method of two points boundary problems, Ukrania,Math.J.,Tom (33),Kiev,(1976),800-835.

7. M.M. Rama, Ordinary Differential Equations Theory and Applications, United Kingdom, (1981), 266 pages.

8. O.Plaat, Ordinary Differential Equations, Holden-Day, Inc.San Francisco,Cambridge,Londan,A msterdam ,1971) 295 pages . 